\title{
Effect of Guidance and Counseling on Students' Emotional Stability: A Case of Higher Learning Institutions in Arusha, Tanzania
}

\author{
Yohana Rogasian Martin \\ Orcid: https://orcid.org/0000-0002-0243-6567 \\ Department of Curriculum and Teaching, University of Arusha, Tanzania \\ Email: janerogasian@yahoo.com \\ Joshua Michael Kuboja, PhD \\ Orcid: https://orcid.org/0000-0002-9585-6914 \\ Department of Curriculum and Teaching, University of Arusha, Tanzania \\ Email: jkuboja@uoa.ac.tz
}

Corresponding Mail: jkuboja@uoa.ac.tz

\begin{abstract}
Copyright resides with the author(s) in terms of the Creative Commons Attribution CC BY-NC 4.0. The users may copy, distribute, transmit and adapt the work, but must recognize the author(s) and the East African Journal of Education and Social Sciences
\end{abstract}

\begin{abstract}
This study sought to establish how guidance and counseling can bring about students' emotional stability in higher learning institution. The study employed a descriptive-correlational design where a self-constructed questionnaire was used as a tool for data collection from a sample of 354 out of the population of 4500 students in two higher learning institutions. Data analysis was done through descriptive statistics which involved the calculation of means and standard deviations for research questions one and two. Pearson Product Moment Correlation Coefficient was used to determine the relationship between the studied variables in research question three. The researchers ensured that sampled respondents voluntarily participated in the study by filling the questionnaire. The information collected was kept confidential and was used for this study only. It is concluded that guidance and counseling services in the studied area are partially done or not done at all. Students can manage their emotional stability if deliberate measures on guidance and counseling are made mandatory. There is a significant and strong positive relationship between Guidance and Counseling services and students' emotional stability. The study recommends that higher learning institutions should deliberately institute the guidance and counseling units where students will have the opportunity to participate. This will guarantee elimination of uncouth behaviors among students whilst improving confidence in them as they pursue their studies.
\end{abstract}

Keywords: Guidance and counseling; Emotional stability; counseling services; quality service

How to cite: Martin, Y. G. and Kuboja, J. M. (2022). Effect of Guidance and Counseling on Students' Emotional Stability: A Case of Higher Learning Institutions in Arusha, Tanzania. East African Journal of Education and Social Sciences 3(1), 94-101. Doi: https://doi.org/10.46606/eajess2022v03i01.0151.

\section{Introduction}

Guidance and counseling are important for students at all levels of education. Through guidance and counseling, students are advised on how to cope with different situations they tend to face in their school life (Sharp and Theiler, 2018). Students are also given proper guidance on how to deal with psychological problems which can badly impact their studies. Through guidance and counseling, students can develop certain problem-solving skills which help them deal with particular issues surrounding their lives, thus promoting emotional stability (Gatua, 2016). 
Effective guidance and counseling services, especially in higher learning institutions have become significant and vital in promoting students' well-being. The services enable students to manage their studies and participate well in a selfdetermined manner (Cheruiyot and Orodho, 2015). According to Meaney, Hasking and Reupert (2016), students who are not able to control their emotions normally misbehave with their classmates, roommates, teachers, etc. thus they became dangerous to society. Thus, emotional stability is essential for one's growth and development. Therefore, teachers should train students how to take control, maintain and develop emotions which are present in every activity and are prime movers of thought and conduct.

Worldwide studies have been conducted about the effects of guidance and counseling services on students' emotional stability. For example, Vera, Jiménez and Barreto (2017) examined the contemporary public policy on school-based guidance and counseling in Venezuela, Costa Rica and Latin American Countries.The study found that reporting of emotional challenges among students causes emotional instability. The study discovered that most of the emotional challenges that were facing students emanated from the lack of knowledge on emotional management. Latin American countries have strived to make sure that students at all levels including University, are emotionally stable through provision of guidance and counseling services.

Aluede and Adubale (2020) conducted a study on school-based counselors' role as perceived by Nigerian counselors. Findings revealed some commonalities and some potentially important differences. Nigerian counselors considered the educational and career planning dimension as the most important dimension in helping to shape students' career choices. The study further indicated that Nigerian counselors considered that counseling is necessary for schools and colleges to help students from stress and depression.

A study in Zambia on nature and benefits of guidance and counseling services offered in selected public secondary schools in Mansa District by Mwape (2015) found that with regards to the nature of guidance and counseling services offered, not all the components of guidance and counseling services were offered. The schools sampled had no guidance and counseling program to follow and teachers were not trained but just seconded to the section. The study concluded that even though pupils faced several challenges, little was done in the provision of guidance and counseling services in the schools sampled and many pupils did not benefit much, thus their emotional stability was in question.

In Kenya, Cheruiyot and Orodho (2015) examined the practice of guidance and counseling in secondary schools. The study established that approximately two-thirds of the practicing school guidance and counseling personnel did not have the required qualifications of a diploma and above. Guidance and Counseling facilities were too inadequate to facilitate effective implementation of Guidance and Counseling services in most schools. Based on the findings, it was recommended that regular workshops on Guidance and Counseling for public secondary school teachers and other service providers be intensified to enable them to improve significantly in pedagogy and effectiveness should be deployed proportionally in schools to enable them deliverer effective services to students.

In Tanzania, studies have been conducted on the role of guidance and Counseling in the education sector. For instance, Rushahu, (2017) examined guidance and counseling services to students with disabilities in higher learning institutions in Tanzania and revealed that despite the significance of guidance and counseling services in higher learning institutions, most of the institutions did not provide the service because of the negative perception about the service and inadequate facilities to run the whole process.

Shuma (2017) studied the enhancing employability skills among higher learning students through career guidance and counseling at two universities in Dodoma. The study reported that higher learning students were aware of the available career guidance and counseling services; however, career guidance and counseling were inadequate, something that was seen to threaten students' acquisition of employability skills. Apart from their importance in promoting students' employability skills, career guidance and counseling services were found not to be formalized within the higher learning institutions; no professional career counselors were found. This study sought to examine the effect of guidance and counseling services on students' emotional stability among higher learning institutions in Arusha City. 


\section{Literature Review}

\section{Emotional Stability}

Emotions have an influential value in life, control of emotions is essential for a prosperous life. A transition from elementary to high school presents a very profound change and a potential source of stress, as it often requires young adolescents to make significant professional decisions. A person who fails to control his or her emotions faces a lot of problems in day-to-day life. Emotional stability results into happy and adjustable life. Therefore, emotional stability is an important aspect of human life and is an important indicator of mental health (Biasi, Mallia, Menozzi and Patrizi, 2015; Yavuz, Cayirdag, Dahir \& Gümüşeli, 2017).

Arora and Rangnekar (2015) studied the relationships between emotional stability, psychosocial mentoring support and career resilience. The study revealed that students who have no control over their emotions misbehave with their classmates, roommates, teachers, etc. Thus, they became dangerous in society. Emotional stability is essential for educational growth and development; teachers should therefore train students how to take control, maintain and develop emotions which are present in every activity and they are prime movers of thoughts and conduct.

A study by Bubić and Ivanišević (2016) on the role of emotional stability and competence in young adolescents' career judgments indicated emotional competence as a statistically significant predictor of a career decision, self-efficacy and emotional stability was revealed as a significant predictor of career concerns. Furthermore, a moderating effect of gender and a mediating role of career decision self-efficacy were revealed in this context. These findings provide novel evidence regarding the complex relationship between individuals' vocational self-beliefs and emotional processing and may be informative for vocational guidance interventions targeted at young adolescents undergoing similar educational transitions.

Arora and Rangnekar (2015) found that the emotional stability dimension is recognized as a significant predictor of academic and behavioral achievement among higher learning students. Low scorers on emotional stability are labeled as neurotic individuals who tend to display ineffective coping mechanisms. They cannot find a constructive solution to a problem and show their indecisiveness very often. Further, Setiyowati, Pali,Wiyono and
Triyono (2019) indicated that low emotional stability suggests an individual's constant struggle with feelings of insecurity and self-consciousness. Such people are prone to psychiatric problems. Thus, lower scores on this factor experience a range of negative emotions, such as stress, anxiety, anger, embarrassment, disgust, guilt and fear. Higher scores on this factor tend to remain self-assured, calm and free from fluctuating and disturbing emotions which may have been avoided should guidance and counseling services received the priority it deserves in the life of the youth ahead of time.

\section{Need for Guidance and Counseling}

Literature from a global context has indicated the existence of a relationship between guidance and counseling services and students' emotional stability. It is shown that effective guidance and counseling services, especially in higher learning institutions have become significant and vital in promoting students' emotional stability. The services aim at enabling students to manage their studies and participate well in the institutions in a self-determined manner while remaining emotionally stable. Thus, emotional stability is essential for educational growth and development (Cheruiyot and Orodho, 2015; Meaney, Hasking, and Reupert, 2016; Supriyanto, Hartini, Syamsudin \& Sutoyo, 2019).

The objective of education is to provide opportunities for students to reach their full potentials in the areas of educational, vocational, social, and emotional development. According to Tsikati (2018), guidance and counseling are the bedrock for achieving self-actualization. It helps students to discover their needs, interests and capabilities, to formulate their own goals and make plans to realize them. The more sufficient the guidance and counseling services offered to University students, the less the degree of difficulty they experience in their lives. Guidance and counseling programs help students develop competencies in academic achievement, personal, emotional, social development and career planning (Lasode, Lawal \& Ofodile, 2017).

The need for guidance and counseling in Tanzania education is being recognized more now than ever before. However, available literature shows that students in higher learning institutions in Tanzania experience serious psychological and emotional problems that affect their academic achievement 
and their wellbeing in general. Rushahu, (2017) found that most of the higher learning institutions in Tanzania do not provide guidance and counseling services because of the negative perception about the service and inadequate facilities to handle the process of guidance and counseling. Ntilisinda (2017) examined the effectiveness of guidance and counseling in facilitating learning among secondary school students in Tanzania. Despite the efforts made by the government of Tanzania and other stakeholders to ensure guidance and counseling is well-practiced in educational institutions, most of the institutions still lag behind the schedule. It is from this context that the researchers sought to examine the effect of guidance and counseling services on students' emotional stability among higher learning institutions in Arusha City. The study sought to address the following research questions:

1. Is quality service on guidance and counseling provided in higher learning institutions in Arusha City?

2. What is the level of students' emotional stability in higher learning institutions?

3. Is there any significant relationship between guidance and counseling services and students' emotional stability?

\section{Methodology}

\section{Research Design}

This study used the Descriptive-correlational survey research design. According to Mohajan (2017), descriptive-correlational survey design is a framework for planning a study in a coherent maner and report the numbers the way they appear without manipulation. The design was suitable in this study because it reported things the way they are and explained the relationship between variables.

\section{Population and Sampling}

The target population of the study was 4500 students from two public higher learning institutions in Arusha City. Out of the 4500 students, 354 were sampled through sub stratified random sampling technique. Out of the 354 sampled respondents, 188 were males and 153 were females.

\section{Instruments}

Data was collected by using a questionnaires. According to Taherdoost (2017), questionnaires cover a large number and area compared to other instruments. Through questionnaire, biases are reduced. Furthermore, questionnaires are less expensive and do not consume a lot of time in the administration. The closed-ended questionnaire was prepared in the English language and it had four options for respondents to indicate their agreement or disagreement as follows: 1 = Strongly Disagree, 2 = Disagree; 3= Agree, 4= Strongly Agree.

\section{Validity and Reliability}

Content and construct validity of the questionnaire were improved through the opinions of seasoned researchers from a higher learning institution whom the researchers consulted for their expertise. Content and constructs were shaken off, improved and modified to suit the objective of the study.

To ensure the reliability of data, a pilot study was administered to 33 students at a higher learning institution which was not part of the sample. The reliability of the questionnaire was tested through the Statistical Package for Social Science (SPSS) and the results yielded the Cronbach's Alpha of above 0.7 which means the data collection instrument was reliable.

\section{Statistical Treatment of Data}

Data analysis was done through descriptive statistics which involved the calculation of means and standard deviations for research questions one and two. Pearson Product Moment Correlation Coefficient was used to determine the relationship between the studied variables in research question three.

\section{Ethical Consideration}

The researchers sought the introduction letter from the University of Arusha and the data collection permit from the Arusha City Executive Director. The permission allowed the researchers to collect data in a specified period. The researchers ensured that sampled respondents voluntarily participated in the study by filling the questionnaire. The information collected was kept confidential and was used for this study only.

\section{Findings and Discussion}

The results section was guided by the aforelisted three research questions as follows:

Research Question 1: Is quality service on guidance and counseling provided in higher learning institutions in Arusha City?

As indicated in Table 1 (p. 97) respondents were exposed to 8 items in the questionnaire to indicate their agreement or disagreement over the availability of guidance and counseling services in their institutions. The general Mean $(M=2.3582)$ 
lies in the disagreement zone $(1.50-2.49)$ meaning that respondents disagreed that guidance and counseling services are provided in their institutions. For example, no special unit was assigned for guidance and counseling in the institutions ( $M=2.2296$; $S D=.74606)$; Students seemed not to be aware of the availability of this service ( $M=1.7625 ; S D=.69670)$; No adequate resources for guidance and counseling ( $M=1.6138$;
SD = .98731); however, students admitted that guidance and counseling is useful $(M=3.6048 ; S D=$ .96769). Out of the eight items in table 1 , only one item showed an agreement that guidance and counseling services are helpful to students while the rest seven items indicated that guidance and counseling services are either poorly done or not done at all.

Table 1: The practice of Guidance and Counseling services at higher learning institutions

\begin{tabular}{lllll}
\hline SN & \multicolumn{1}{c}{ Items in the Questionnaire } & Mean & Std. Dev & Interpretation \\
\hline 1 & Guidance and counseling is practiced in our Institution & 1.3269 & .62396 & Strongly disagree \\
2 & There is a special unit for guidance and counseling at our college & 2.2296 & .74606 & Disagree \\
3 & I am aware of the availability of guidance and counseling services & 1.7625 & .69670 & Disagree \\
4 & Guidance and counseling is practiced at the required standard & 1.7478 & .51122 & Disagree \\
5 & Guidance and counseling is practiced regularly & 2.3250 & .72679 & Disagree \\
6 & The guidance and counseling modality is helpful to students & 3.6048 & .96769 & Strongly Agree \\
7 & There is adequate material and moral support from the Institution's & 2.2048 & .76769 Disagree \\
8 & There are adequate resources for guidance and counseling & 1.6138 & .98731 & Disagree \\
& Average M and SD & $\mathbf{2 . 3 5 8 2}$ &. $\mathbf{8 4 5 6 3}$ Disagree \\
\hline
\end{tabular}

Table 2: Emotional Stability of Students

\begin{tabular}{llccc}
\hline SN & \multicolumn{1}{c}{ Items in the Questionnaire } & Mean & Std. Dev & Interpretation \\
\hline 1 & I can manage myself & 3.3296 & .94606 & high \\
2 & I can handle my temper & 2.3144 & .95309 & Low \\
3 & I can handle my stress & 2.3123 & .92988 & Low \\
4 & I have self-control & 3.4625 & .99670 & high \\
5 & I can manage the feelings of anxiety & 2.0865 & 1.21595 & Low \\
6 & I can manage the feelings of guilt & 2.2865 & .71595 & Low \\
7 & I'm able to solve my emotional problems & 2.4865 & 1.21595 & Low \\
8 & I can manage the feelings of insecurity and self-consciousness & 2.3220 & .80492 & Low \\
9 & I can manage the feelings of fear & 2.4420 & .95183 & Low \\
& Average M and SD & $\mathbf{2 . 3 0 6 1}$ & .96748 & Low \\
\hline
\end{tabular}

The findings have much in common with what other studies have found out elsewhere such as in Zambia, Kenya and Tanzania. For example, a study done in Zambia by Mwape (2015) found that with regards to the nature of guidance and counseling services offered, not all the component were offered. Only examination talks were reported to be significantly offered. The schools sampled had no guidance and counseling program to follow and teachers were not trained but were just seconded to the section. The study also revealed that pupils had not benefited much from the services offered. The study concluded that even though pupils faced challenges, little was done in the provision of guidance and counseling services and many did not benefit much.

In Kenya, Cheruiyot and Orodho (2015) examined the practice of guidance and counseling in secondary schools. The study established that approximately two-thirds of the practicing school guidance and counseling personnel did not have the required qualifications of a diploma and above. Guidance and Counseling facilities were too inadequate to facilitate effective implementation of Guidance and Counseling services. In Tanzania, studies have been conducted on the role of guidance and Counseling in the education sector. For instance, Rushahu, (2017) examined the guidance and counseling services to students with disabilities in higher learning institutions. The study revealed that despite the significance of guidance and counseling services in higher learning institutions, most of the institutions did not provide this service because of inadequate facilities.

Research Question 2: What is the level of students' emotional stability in higher learning institutions in Arusha City?

Responding to the questionnaire items as reflected in table 2, it was found that management of stress ( $M=2.3123 ; S D=.92988$ ); management of temper ( $M=2.3144 ; S D=.95309)$, management of guilt 
feeling ( $M=2.2865 ; S D=.71595)$, management of fear and insecurity $(M=2.3220 ; S D=.810492)$ and management of self-control $(2.4625, \mathrm{SD}=.99670)$ lied between 1.50 and 2.49 meaning respondents indicated that they can hardly manage themselves. Students indicated that they are unable to solve emotional problems on their own ( $\mathrm{M}=2.4865$; $\mathrm{SD}=$ 1.21595). Indeed, one cannot solve his emotional problems unless guided by experts.

These findings are supported by Rangnekar (2015) who studied the relationships between emotional stability, psychosocial mentoring support and career resilience. The study revealed that students who have no control over their emotions misbehave with their classmates, roommates, teachers, etc. thus they became dangerous for society. Therefore, emotional stability is essential for educational growth and development; teachers should train students how to take control, maintain and develop emotions.

Research Question 3: Is there any significant relationship between guidance and counseling services and students' emotional stability among higher learning institutions in Arusha City?

Question three sought to establish the relationship between guidance and counseling practices and the emotional stability of students. This question called for testing of a null hypothesis which stated: there is no significant relationship between guidance and counseling services and students' emotional stability in higher learning institutions in Arusha City. The nature of possible correlations was interpreted based on Cohen's formula as follows: $\geq .70=$ strong relationship; $\geq .50=$ moderate relationship and $\leq .50=$ weak relationship.

Table 3: Correlation between Guidance and Counseling and Emotional Stability

\begin{tabular}{llcc}
\hline & & Guidance and Counseling & Emotional Stability \\
\hline Guidance and Counseling & Pearson Correlation & 1 & $.758^{* *}$ \\
& Sig. (2-tailed) & & .000 \\
& $\mathrm{~N}$ & 341 & 341 \\
Emotional Stability & Pearson Correlation & $.758^{* *}$ & 1 \\
& Sig. (2-tailed) & .000 & 341 \\
\hline
\end{tabular}

**. Correlation is significant at the 0.01 level (2-tailed).

As indicated in Table 3, there is a significant and strong positive relationship between Guidance and Counseling services and students' emotional stability (sig. $=.000, r=.758$ ). Hence, the null hypothesis was rejected and researchers maintained that there was a significant relationship between what students achieve emotionally and the support they received from guidance and counseling services. This suggests that guidance and counseling enhance students' emotional stability.

Literature has indicated immensely on the contribution of guidance and counseling towards achieving emotional stability of students who at most times are confronted with tough decision making. Expounding on the same idea, Shuma (2017) sees guidance and counseling as a tool for enhancing employability skills among higher learning students through career guidance and counseling.

Another empirical study done by Sivalingam (2019) on human resource management to optimize the Malaysian school counseling department revealed that most of the higher learning students in Malaysia faced myriads of emotional challenges as a result of peer influence and other unacceptable behaviors like drug abuse. The study further indicated that these emotional problems affected the students' learning and their life in general. It was suggested that to address the problem, guidance and counseling would play a vital role. The other study by Atsuwe and Achebulu (2018) on the influence of guidance and counseling on the academic performance of secondary schools student revealed that school counselors help to make learning a positive experience. Counselors facilitate communication among teachers, parents, administrators and students to adapt the school environment.

\section{Conclusions and Recommendations Conclusion}

It is concluded that guidance and counseling services in the studied area are partially done or not done at all. This revelation is shocking especially when the tools to help administer behavioral change and career pursuance are not made part of the institutional culture. It is further concluded that students can manage their emotional stability if deliberate measures on 
guidance and counseling are made mandatory. Finally, there is a significant and strong positive relationship between Guidance and Counseling services and students' emotional stability.

\section{Recommendations}

Based on the conclusion of this study, the researchers gave the following recommendations:

To improve students' future careers and ensure sound emotional stability, higher learning institutions should deliberately institute the guidance and counseling units where students will have the opportunity to participate. This will guarantee elimination of uncouth behaviors among students whilst improving confidence in them as they pursue their studies.

Emotional stability will only improve when students are made aware of the services and their application in life. It is therefore, recommended that the higher learning institution administrators should take the initiative to capitalize on this crucial component if they are to command maximum respect from students.

\section{References}

Aluede, O., \& Adubale, A. A. (2020). SchoolBased Counsellors' Role as Perceived by Nigerian Counselors. Journal of SchoolBased Counseling Policy and Evaluation, 2(1), 56-62.

Arora, R., \& Rangnekar, S. (2015). Relationships between emotional stability, psychosocial mentoring support, and career resilience. Europe's journal of psychology, 1(2), 39-57.

Atsuwe, B. A., \& Achebulu, A. O. (2018). The Influence of Guidance and Counselling On Academic Performance of Secondary Schools Student in Makurdi Local Government Area, Benue State. International Journal of Educational Studies, 5(2), 71-78.

Biasi, V., Mallia, L., Menozzi, F., \& Patrizi, N. (2015). Adaptive functioning and behavioral, emotional and social problems of Italian university students: Indications for the University Counseling Services. ProcediaSocial and Behavioral Sciences, 2(5), 66-69.
Bubić, A., \& Ivanišević, K. (2016). The role of emotional stability and competence in young adolescents' career judgments. Journal of Career Development, 43(6), 498511.

Cheruiyot, D. K., \& Orodho, J. A. (2015). Guidance and Counselling: What is the Level of Human and Physical Resource Preparedness in Providing Effective Services in Secondary Schools in Bureti Sub County, Kericho County, Kenya?. Journal of Education and Practice, 6(23), 132-143.

Gatua, D. M. (2016). Impact of guidance and counseling services on students' social and emotional adjustment in Public Urban and Rural Secondary Schools in Nakuru and Uasin Gishu Counties, Kenya. International Journal of Science and Research (IJSR) ISSN .

Lasode, A. O., Lawal, O. O., \& Ofodile, M. C. (2017). Students' need for, awareness, perception, and use of guidance and counseling services in federal university of agriculture, Abeokuta, Nigeria. Problems of Education in the 21st Century, 75(2), 170.

Meaney, R., Hasking, P., \& Reupert, A. (2016). Borderline personality disorder symptoms in college students: the complex interplay between alexithymia, emotional dysregulation, and rumination. PloS one, 11(6), e0157294.

Mohajan, H. K. (2017). Two criteria for good measurements in research: Validity and reliability.Annals of Spiru Haret University. Economic Series, 17(4), 59-82.

Mwape, J. (2015). Nature and benefits of guidance and counseling services offered in selected public secondary schools in Mansa district (Doctoral dissertation, University of Zambia).

Ntilisinda, J.W. (2017). The Effectiveness of Guidance and Counseling in Facilitating Learning among Secondary School Students in Tanzania: A Case Study of Dodoma Municipality. Master's Thesis, University of Dodoma.

Rangnekar, S. (2015). Relationships between emotional stability, psychosocial mentoring support, and career resilience. Europe's journal of psychology, 11(1), 16 
Rushahu, B. G. (2017). Guidance and Counseling Services to Students with Disabilities in Higher Learning Institutions in TanzaniaPractices and Implications. Doctoral dissertation, Carl von Ossietzky Universität Oldenburg.

Setiyowati, A. J., Pali, M., Wiyono, B. B., \& Triyono, T. (2019). Structural model of counseling competence. Journal Cakrawala Pendidikan, 38(1), 45-62.

Sharp, J., and Theiler, S. (2018). A review of psychological distress among university students: Pervasiveness, implications, and potential points of intervention. International Journal for the Advancement of Counselling, 40(3), 193-212.

Shuma, C. J. (2017). Enhancing employability skills among higher learning students through career guidance and counseling: experience from the University of Dodoma and St. John's University of Tanzania. Doctoral dissertation, The University of Dodoma.

Sivalingam, A. (2019). An empirical study in human resource management to optimize. Malaysian School Counseling Department. International Journal of Financial Research, 10(5).
Supriyanto, A., Hartini, S., Syamsudin, S., \& Sutoyo, A. (2019). Indicators of professional competencies in research of Guidance and Counseling Teachers. Counsellia: Jurnal Bimbingan dan Konseling, 9(1), 53-64.

Taherdoost, H. (2017). How to calculate survey sample size. The International Journal of Economics and Management Systems, 4(2), 21-32.

Tsikati. A. F. (2018). Factors contributing to effective guidance and counseling services at The University of Eswatini. Global Journal of Guidance and Counselling in Schools: Current Perspectives, 8(3), 139-148.

Vera, G. D., Jiménez, D., \& Barreto, A. (2017). Contemporary public policy on school-based guidance and counseling in Venezuela, Costa Rica, and other Latin American Countries. International Handbook for Policy Research on School-Based Counseling (pp. 473-483). Springer, Cham.

Yavuz, O., Cayirdag, N., Dahir, C., \& Gümüşeli, A. I. (2017). Improving student achievement through strengthening principal and school counselor partnership. International Journal of Educational Reform, 26(2), 176-201. 